\title{
Editorial corner
}

\section{The first impact factor has been given to Express Polymer Letters}

\author{
T. Czigány*
}

Department of Polymer Engineering, Budapest University of Technology and Economics, Múegyetem rkp. 3., H-1111, Budapest, Hungary

Express Polymer Letters, a journal launched in January 2007 , achieved a great success by the fact that the Journal Citation Reports ${ }^{\circledR}$ of 2009, issued by Thomson Reuters, published the first calculated impact factor of the journal, which is 1.452 (The impact factor of a journal is the average number of citations in a given year to those papers that were published during the two preceding years).

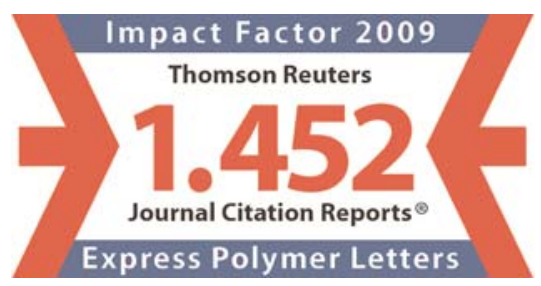

By this impressive initial impact factor the high level of eXPRESS Polymer Letters has been acknowledged, which means that we are already within the first half of all journals with impact factor all over the world. Taking into account these journals dealing with polymers or polymer related materials science and technology topics, eXPRESS Polymer Letters is already within the first third of them. This rapid and remarkable result was generated by the consequent, rigorous peer reviewing process and by the good quality, predictable and reliable publication. In the past 3 years researchers of almost 60 countries submitted articles to eXPRESS Polymer Letters, but only about $30 \%$ of it was finally accepted. The continuously improving quality of the papers and the growing recognition of eXPRESS Polymer Letters is proven by the fact that the number of downloads doubles every

"Corresponding author, e-mail: czigany@ @eik.bme.hu (C) BME-PT year. From the articles published in the journal most cited and downloaded are those related to preparation and properties of nano-, bio- and selfreinforced composites and to self-healing properties of special materials, to certain technologies (such as e.g. polymer welding) and to natural polymers and their composites.

Although it is quite hard to become a member of the journal family having impact factor, it is much easier to lose this position. Therefore eXPRESS Polymer Letters makes the acceptance and approval process of the submitted papers even stricter. We do not strive for quantity, rather for quality, therefore we do not plan to increase the number of articles published in a month (presently 8-10). We wish to publish only original articles and we do our best to maintain the fast reviewing and publishing process (presently on an average 3-4 months).

Of course, this success could not have been achieved without the continuous cooperation and help of our authors, reviewers and readers, which is very much acknowledged and counted on in the future as well. This is the right occasion to thank all my colleagues of the Editorial for their hard work!

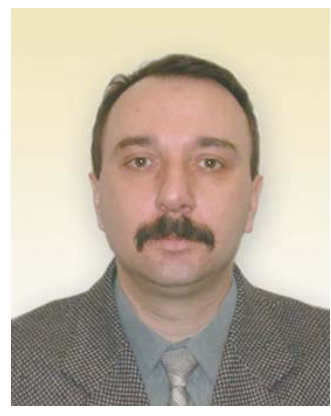

Prof. Dr. Tibor Czigány Editor of Express Polymer Letters 